\title{
Major Variation in Branches of the Abdominal Aorta in New Zealand White Rabbit (Orycotolagus Cuniculus)
}

\author{
Ahasan ASML ${ }^{1 *}$, Islam MS ${ }^{2}$, Kabria ASMG ${ }^{1}$, Rahman $\mathrm{ML}^{1}$, Hassan $\mathrm{MM}^{3}$ and Uddin $\mathrm{M}^{1}$ \\ ${ }^{I}$ Department of Anatomy and Histology, ${ }^{2}$ Department of Pathology and Parasitology, \\ ${ }^{3}$ Department of Physiology, Biochemistry and Pharmacology. Faculty of Veterinary Medicine, Chittagong \\ Veterinary and Animal Sciences University, Khulshi, Chittagong-4202, Bangladesh
}

[Received: October 25, Accepted: December 29, 2012]

\begin{abstract}
The aim of the present study was to investigate the arrangement and major vascular variation of abdominal aorta in NZW rabbit. A total of 28 healthy adult rabbits (14 males and 14 females) with an average $(1.3 \pm 0.5 \mathrm{~kg})$ body weight were used in this study. Deep surgical anaesthesia was done by using combination of xylazine and ketamine at the doses of $10 \mathrm{mg} / \mathrm{kg}$ and $40 \mathrm{mg} / \mathrm{kg}$ body weight respectively, and was sacrificed by bleeding through the right ventricle of the heart. Cannulation of the thoracic aorta and stained latex (added with ammonium water and red carmine stain) injection were performed, followed by $10 \%$ neutral buffered formalin. Asymmetry of the even branches with their distribution and the way of departure of the arteries from the abdominal aorta were observed. However, double pair ovarian arteries were found in a single animal. The diameter of the caudal mesenteric artery showed significant $(p \leq 0.05)$ difference between male and female. In case of male and female, the variability of the origin (number and level of origin) of testicular, ovarian and profound iliac circumflex arteries was also observed.
\end{abstract}

Keywords: Abdominal aorta, New Zealand white rabbit, Arteries

\section{INTRODUCTION}

The morphological variation in various structures of living organisms (animals and plants kingdom) is a common observable fact. There are a great number of experiments where laboratory animals like rabbit are using worldwide. Different articles described widespread details attention to the body structure and organ systems $[1,2,3,4,5]$. Anatomical studies on abdominal aorta that supplies the abdominal viscera are necessary to know the pattern of blood supply and to mitigate vascular obstruction in different clinical and pathological condition. In different breeds of rabbit show variation in the aorta as well as other domestic animal species ${ }^{[6]}$. Moreover, the aorta structure-internal vascular layer variations and the pattern of aortic arch were described in NZW rabbit ${ }^{[7,8]}$.

Laboratory animals provided at varying extent of knowledge, for example experimental surgical interventions, pathological mechanisms, effects of some drugs on the nervous system and other systems which can be applied not only to domestic animals but also to humans ${ }^{[9]}$. Furthermore, as an excellent model species, rabbit helps to investigate such conditions like arterial injury [10, 11, 12], aortic occlusion ${ }^{[13,14]}$ and aortic aneurysm ${ }^{[15]}$. However, there is limited information about basic morphometrics on the abdominal aorta. The aim of the present study was to describe major morphological variations of the abdominal aorta of
NZW rabbit in order to inform the experimental research and clinical practices.

\section{MATERIALS AND METHODS}

A total of 28 healthy adult NZW rabbit (14 males and 14 females) of both sexes weighing (BW) male$1.39 \pm 0.045 \mathrm{~kg}$ and female- $1.20 \pm 0.059 \mathrm{~kg}$, respectively that was collected from Chittagong Metropolitan Market, and were housed individually in wire-rod-floored stainless-steel cages. The rabbits were quarantined (10 days) before dissection to allow adaptation to environmental conditions, food, and water. The rabbits were provided with standard rabbit diet $(75 \mathrm{gm})$ daily and adlibitum fresh water, and were subjected to daily evaluation of health status during the quarantine period. All the rabbits were clinically healthy prior to dissections. The research was conducted according to the guidelines of the Council of the European Union, and following proper guideline for care, handling and experimental procedure for laboratory animal.

Deep surgical anaesthesia was performed by using Xylazine Hydrochloride (Xylaxin $^{\circledR}$, Indian Immunologicals Ltd., India) at a dose of $10 \mathrm{mg} / \mathrm{kg}$ b.w. and ketamine Hydrochloride (G-ketemine ${ }^{\circledR}$, Gonoshasthaya Pharmaceuticals Ltd., Bangladesh) at a dose of $40 \mathrm{mg} / \mathrm{kg} \mathrm{BW}$ intramuscularly followed by the method described earlier ${ }^{[7]}$. After general anaesthesia, rabbits were positioned dorso-ventraly for dissection. Thoracic cage were opened by longitudinal incision through costo-chondral junction 
to expose the heart. All the rabbits were sacrificed by removing blood through right ventricle of the heart. After removal of blood, thoracic aorta were dissected in in situ condition and cannulated to fix them with an average $30 \mathrm{ml}$ of $10 \%$ formaldehyde, and rabbits were kept in room temperature for an hour. After one hour, the arterial system was flushed with normal saline by making a counter opening in femoral artery. Average $5 \mathrm{ml}$ of latex added with ammonium water and red carmine stain was injected to fill the arteries via the thoracic aorta and the rabbits were kept for twenty four hours in room temperature. Later, lengths and diameters of the major branches of the abdominal aorta were measured. The diameters of celiac trunk, cranial mesenteric artery, renal arteries, cranial abdominal arteries, caudal mesenteric artery, median caudal artery, profound iliac circumflex arteries, external iliac arteries, and internal iliac arteries were measured appropriately by using digital slide calipers Mitutoyo Digital Caliper CD-S15C, Tokkyo, Japan. Besides, the measurements of diameter, we also took the length of the celiac trunk (before dividing into common trunk for hepatic, gastro duodenal and right gastric artery and common trunk for splenic and left gastric artery), cranial mesenteric trunk (up to the level of origin of jejunal artery and iliocecocolic artery), length of the abdominal aorta from the aortic hiatus to bifurcation of common iliac artery, total length of aorta from the aortic arch to bifurcation of common iliac arteries, distance between celiac trunk and cranial mesenteric artery, distance between renal arteries and the distance between cranial and caudal mesenteric arteries, distance between testicular and ovarian artery. Photograph of the different arteries were taken by using a digital camera (Sony, Cybershot, China).

The obtained data were imported and stored in Excel-2000 and analyzed by using software-STATA11.0 (Stata Crop., College Station, Tx, USA). The mean and SEM with $95 \%$ CI were calculated to expressed the different variables. The t-test was used for comparisons of variable between male and female were done and $p \leq 0.05$ were considered for significant.

\section{RESULTS}

Abdominal aorta enters into the abdomen through the aortic hiatus of the diaphragm and ends by the paired common iliac arteries (Figure 1, 2). The mean diameter of the abdominal aorta at the place of descent of the celiac trunk was $(3.21 \pm 0.35 \mathrm{~mm})$ showed no significant variation in male $(3.13 \pm 0.12 \mathrm{~mm})$ and female $(3.21 \pm 0.06 \mathrm{~mm})$.

The first branch of the abdominal aorta in NZW rabbit is celiac artery which divided into two trunks: namely common trunk for hepatic, gastrodoudenal and right gastric artery and common trunk for the splenic and left gastric artery (Fig. 1, 2, 3). The diameter of celiac artery showed no significant differences at $(p>0.05)$ in male $(1.75 \pm 0.054 \mathrm{~mm})$ and female $(1.75 \pm 0.121 \mathrm{~mm})$ (Tab. 1). The average length of celiac trunk was $4.96 \pm 1.65 \mathrm{~mm}$ (Tab. 2).

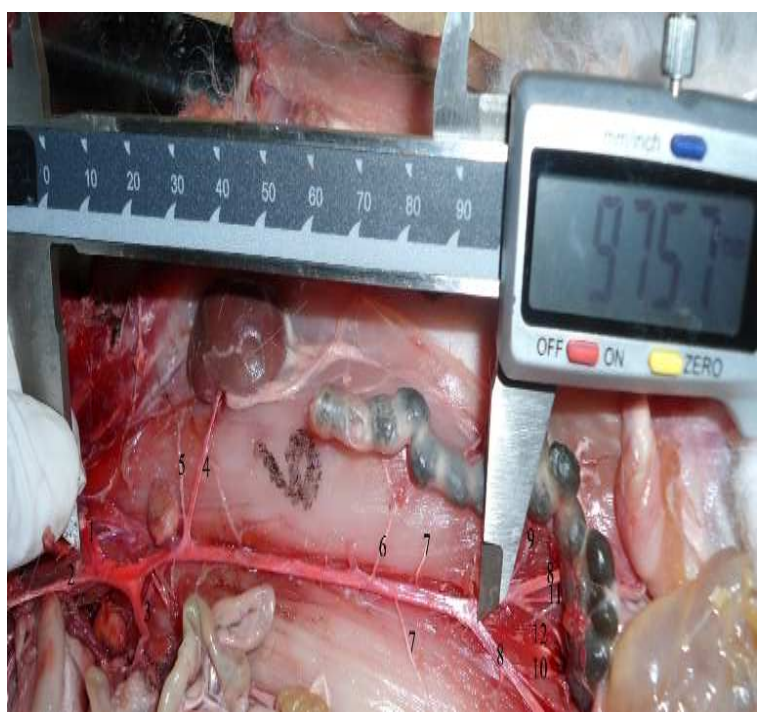

Figure 1. Pattern of abdominal aorta with branches in male New Zealand white rabbit.

1.Abdominal aorta, 2. Celiac trunk, 3. Cranial mesenteric artery, 4. Renal arteries 5. Cranial abdominal arteries, 6. Caudal mesenteric artery, 7. Testicular arteries 8. External iliac arteries, 9. Profund circumflex iliac arteries, 10. Internal iliac arteries, 11. Umbilical arteries, 12. Median caudal artery

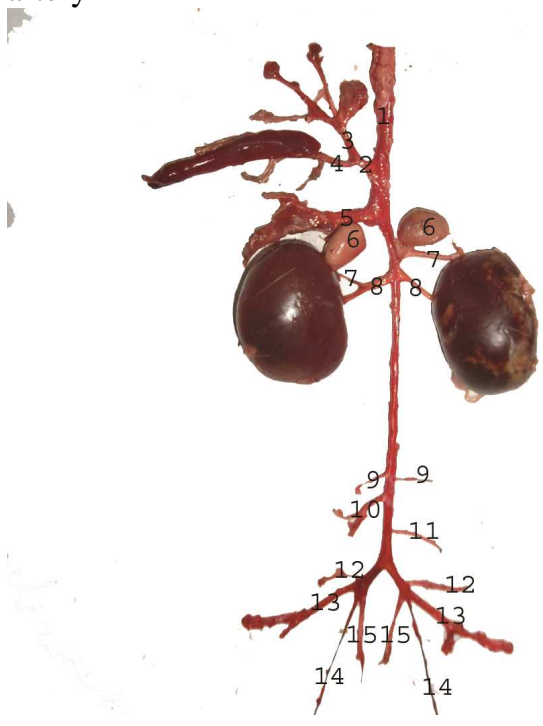

Figure 2. Pattern of abdominal aorta with branches in female New Zealand white rabbit.

1. Abdominal aorta, 2. Celiac Trunk, 3. Common trunk for hepatic, gastroduodenal and right gastric arteries 4. Common trunk for splenic and left gastric arteries, 5. Cranial mesenteric artery, 6. Adrenal gland, 7. Cranial abdominal arteries, 8. Renal arteries 9. Ovarian arteries, 10. Caudal mesenteric artery 11. Median Caudal artery, 12.profound iliac circumflex arteries, 13. External iliac arteries, 14. Umbilical arteries, 15. Internal iliac arteries 
Table 1. Measurements of diameter of abdominal aorta and its branches in compare with male and female.

\begin{tabular}{|c|c|c|c|c|c|}
\hline Variables & $\begin{array}{l}\text { Overall mean } \pm \\
\text { SEM }(\mathrm{mm})\end{array}$ & Sex & Mean \pm SEM $(\mathrm{mm})$ & t-value & p-value \\
\hline \multirow{2}{*}{$\begin{array}{l}\text { Abdominal aorta (at the } \\
\text { place of descent of } \\
\text { celiac trunk) }\end{array}$} & \multirow[t]{2}{*}{$3.21 \pm 0.35$} & Male & $3.13 \pm 0.12$ & \multirow[t]{2}{*}{-0.51} & \multirow[t]{2}{*}{0.62} \\
\hline & & Female & $3.21 \pm 0.06$ & & \\
\hline \multirow{2}{*}{ Celiac Artery } & \multirow[t]{2}{*}{$1.75 \pm 0.34$} & Male & $1.75 \pm 0.05$ & \multirow[t]{2}{*}{0.01} & \multirow[t]{2}{*}{0.99} \\
\hline & & Female & $1.75 \pm 0.12$ & & \\
\hline \multirow{2}{*}{$\begin{array}{l}\text { Cranial mesenteric } \\
\text { artery }\end{array}$} & \multirow[t]{2}{*}{$2.25 \pm 0.33$} & Male & $2.18 \pm 0.05$ & \multirow[t]{2}{*}{-1.28} & \multirow[t]{2}{*}{0.22} \\
\hline & & Female & $2.33 \pm 0.10$ & & \\
\hline \multirow[t]{2}{*}{ Right renal artery } & \multirow[t]{2}{*}{$1.26 \pm 0.24$} & Male & $1.32 \pm 0.08$ & \multirow[t]{2}{*}{0.49} & \multirow[t]{2}{*}{0.63} \\
\hline & & Female & $1.26 \pm 0.06$ & & \\
\hline \multirow[t]{2}{*}{ Left renal artery } & \multirow[t]{2}{*}{$1.32 \pm 0.28$} & Male & $1.38 \pm 0.08$ & \multirow[t]{2}{*}{0.99} & \multirow[t]{2}{*}{0.35} \\
\hline & & Female & $1.27 \pm 0.06$ & & \\
\hline \multirow{2}{*}{$\begin{array}{l}\text { Right cranial abdominal } \\
\text { artery }\end{array}$} & \multirow[t]{2}{*}{$0.44 \pm 0.11$} & Male & $0.47 \pm 0.03$ & \multirow[t]{2}{*}{1.67} & \multirow[t]{2}{*}{0.12} \\
\hline & & Female & $0.41 \pm 0.02$ & & \\
\hline \multirow{2}{*}{$\begin{array}{l}\text { Left cranial abdominal } \\
\text { artery }\end{array}$} & \multirow[t]{2}{*}{$0.45 \pm 0.11$} & Male & $0.49 \pm 0.03$ & \multirow[t]{2}{*}{2.20} & \multirow[t]{2}{*}{0.05} \\
\hline & & Female & $0.41 \pm 0.02$ & & \\
\hline \multirow{2}{*}{$\begin{array}{l}\text { Caudal mesenteric } \\
\text { artery }\end{array}$} & \multirow[t]{2}{*}{$0.56 \pm 0.13$} & Male & $0.62 \pm 0.02$ & \multirow[t]{2}{*}{3.11} & 0.01 \\
\hline & & Female & $0.49 \pm 0.03$ & & \\
\hline Median caudal artery & $0.69 \pm 0.19$ & Male & $0.71 \pm 0.05$ & 0.72 & 0.48 \\
\hline & & Female & $0.66 \pm 0.04$ & & \\
\hline Right profound iliac & $0.65 \pm 0.11$ & Male & $0.66 \pm 0.02$ & 0.72 & 0.73 \\
\hline circumtlex artery & & Female & $0.65 \pm 0.03$ & & \\
\hline Left profound iliac & $0.64 \pm 0.12$ & Male & $0.66 \pm 0.03$ & 1.22 & 0.24 \\
\hline circumflex artery & & Female & $0.65 \pm 0.03$ & & \\
\hline Right external iliac & $1.79 \pm 0.29$ & Male & $1.83 \pm 0.06$ & 0.67 & 0.51 \\
\hline & & Female & $1.75 \pm 0.08$ & & \\
\hline Left external iliac artery & $1.72 \pm 0.35$ & Male & $1.71 \pm 0.08$ & -0.13 & 0.90 \\
\hline & & Female & $1.73 \pm 0.10$ & & \\
\hline Right internal iliac & $0.80 \pm 0.21$ & Male & $0.83 \pm 0.053$ & 0.79 & 0.45 \\
\hline artery & & Female & $0.76 \pm 0.06$ & & \\
\hline Left internal iliac artery & $0.78 \pm 0.19$ & Male & $0.79 \pm 0.04$ & 0.09 & 0.93 \\
\hline & & Female & $0.78 \pm 0.05$ & & \\
\hline
\end{tabular}




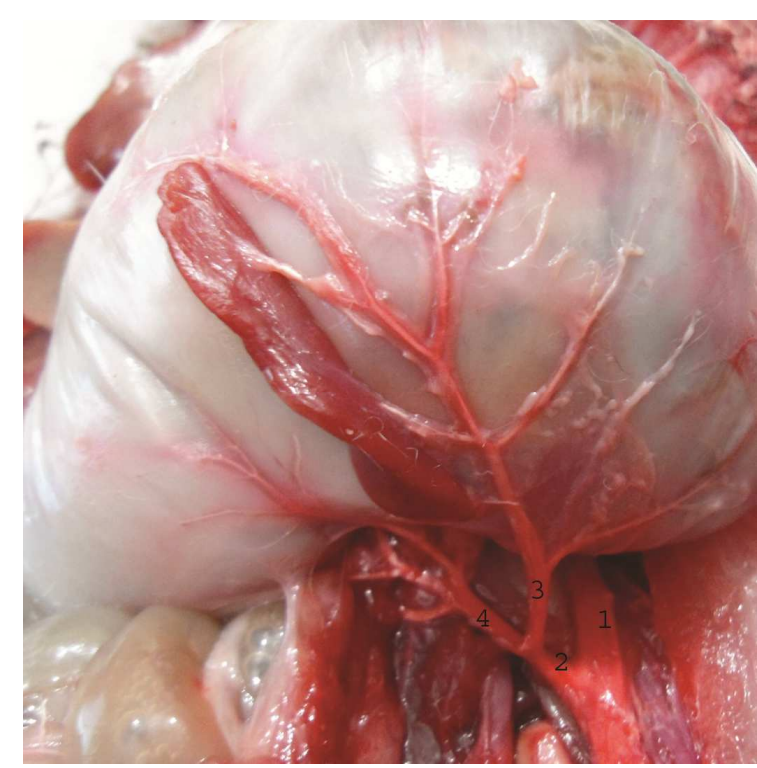

Figure 3. Division of branches of celiac trunk

1. Abdominal aorta 2. Celiac trunk 3. Common trunk for splenic and right gastric arteries 4. Common trunk for heptic, gastroduodenal and right gastric arteries

Behind the celiac trunk there descends cranial mesenteric artery from the abdominal aorta. It is an asymmetrical vessel and its mean diameter (2.25 $\pm 0.33 \mathrm{~mm}$ ) is biggest of all branches of abdominal aorta with larger diameter in female $(2.33 \pm 0.108$ $\mathrm{mm})$ than male $(2.18 \pm 0.05 \mathrm{~mm})$ (Tab. 1). It always descends as a separate branch which gives rise to pancreatic-duodenal artery, middle colic artery, jejunal artery, ileocecocolic artery. The length of the cranial mesenteric trunk was $19.08 \pm 2.59 \mathrm{~mm}$ up to the level of origin of ileocecocolic artery and jejunal artery (Fig. 4) (Tab. 2).

Table 2. Measurements of length of abdominal aorta and its branches

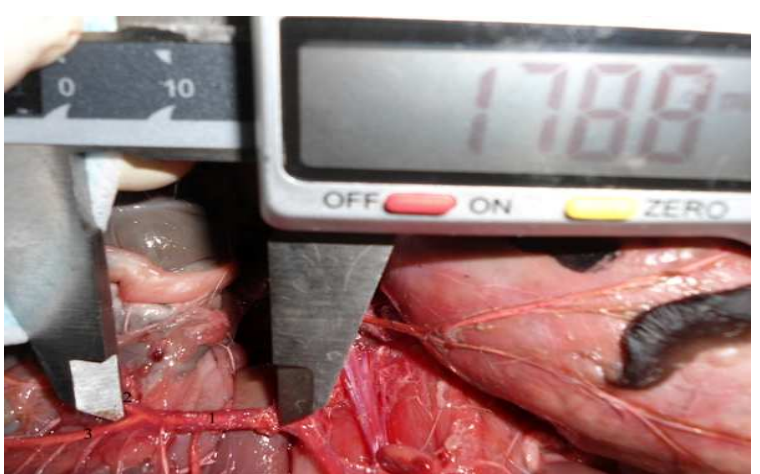

Figure 4. Cranial mesenteric trunk with its major branches

1. Cranial mesenteric trunk, 2. ileocecocolic artery,

3. Jejunal artery

Renal arteries descended as single branches of the abdominal aorta below the cranial mesenteric artery in $28(100 \%)$ cases. The average diameter of right renal artery and left renal artery was $1.26 \pm 0.24 \mathrm{~mm}$ and $1.32 \pm 0.28 \mathrm{~mm}$, respectively. However, in male it was $1.32 \pm 0.08 \mathrm{~mm}$ for right as well as $1.38 \pm 0.08 \mathrm{~mm}$ for left but in female it showed $1.26 \pm 0.06 \mathrm{~mm}$ for right one and $1.27 \pm 0.06 \mathrm{~mm}$ for left renal artery (Tab. 1). In all dissected rabbits, there was variable distance $(4.68 \pm 2.31 \mathrm{~mm})$ between renal arteries (right $\&$ left) except a single case $(3.57 \%)$, where both the renal arteries were originated at the same level from the abdominal aorta (Fig. 5, 6) (Tab. 2).

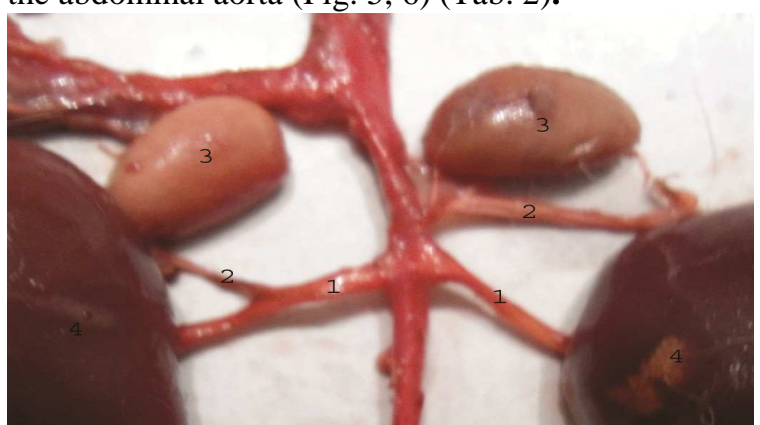

Figure 5. Exceptional pattern of renal arteries and cranial abdominal arteries in NZW rabbit

1. Renal arteries, 2. Cranial Abdominal arteries, 3. Adrenal gland 4. Kidneys

\begin{tabular}{|l|c|c|}
\hline Variables & Mean \pm SEM & Min-Max \\
\hline celiac trunk length (mm) & $4.96 \pm 1.65$ & $2.57-8.18$ \\
\hline Cranial Mesenteric artery length (mm) & $19.08 \pm 2.59$ & $15.1-24.64$ \\
\hline Abdominal aorta length up to bifurcation of common iliac (mm) & $99.31 \pm 6.97$ & $82.8-112.8$ \\
\hline Total length of aorta (aortic arch to bifurcation of common iliac) (cm) & $19.11 \pm 1.22$ & $15.5-21.4$ \\
\hline Distance between Celiac Trunk and cranial mesenteric artery (mm) & $10.29 \pm 1.50$ & $7.37-13.11$ \\
\hline Distance between renal arteries (mm) & $4.68 \pm 2.31$ & $00-8.77$ \\
\hline Distance between cranial and caudal mesentric arteries (mm) & $62.54 \pm 6.52$ & $48.1-75.77$ \\
\hline
\end{tabular}




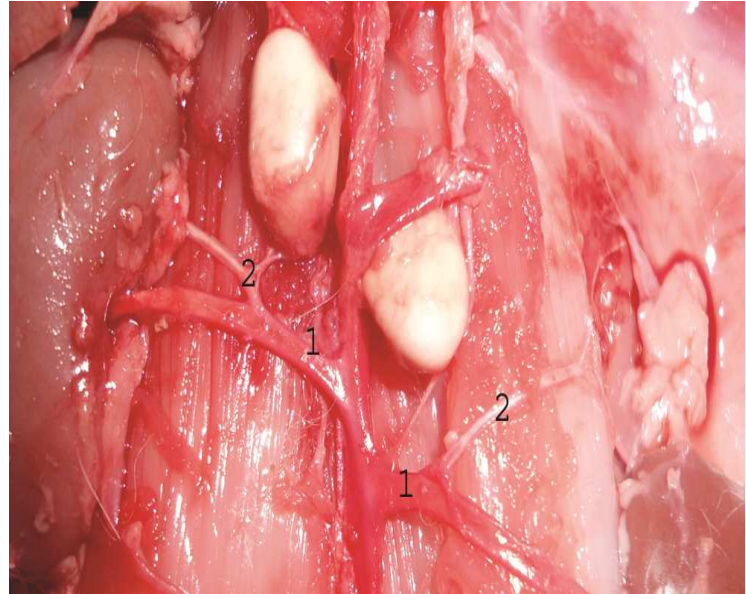

Figure 6. Normal pattern of testicular and cranial abdominal arteries.

1. Renal arteries, 2. Cranial abdominal arteries

In 27 cases $(96.43 \%)$, the right and left cranial abdominal arteries normally descended from the right and left renal arteries, respectively. The differences concerned only the place of descent from the renal artery against the abdominal aorta. But, in a single case $(3.57 \%)$ only the left cranial abdominal artery originated from abdominal aorta directly (Fig. $5,6)$. The mean diameter of right and left cranial abdominal arteries were $0.44 \pm 0.11 \mathrm{~mm}$ and $0.45 \pm 0.1 \mathrm{~mm}$, respectively. In male right one was slightly smaller than left but in female both were similar diameter (Tab. 1)

The mean diameter of caudal mesenteric artery was $0.56 \pm 0.13 \mathrm{~mm}$ with significantly larger diameter in male $(0.62 \pm 0.029)$ than female $(0.49 \pm 0.0 .03)$ (Tab. 1). Mean distance between cranial and caudal mesenteric arteries were 62.54 $\pm 6.52 \mathrm{~mm}$ (Tab. 2).

In 14 male rabbits $(100 \%)$, testicular arteries were descended from the abdominal surface of the aorta below renal arteries. Among them, both testicular arteries were descended above caudal mesenteric artery in 7(50\%) cases and below the caudal mesenteric artery in $4(28.57 \%)$ cases. In case of two individual (14.28\%), one showed that, the left testicular artery descended above the caudal mesenteric artery and the right testicular artery descended below the caudal mesenteric artery and another one revealed that, the left testicular artery descended at the level of caudal mesenteric artery and the right testicular artery descended below the caudal mesenteric artery. But, in a single individual (7.14\%) there was no distance between right and left testicular arteries. In 13 cases, these arteries were asymmetrically descended from each other.

In 14 female rabbits, both right and left ovarian arteries descended above the caudal mesenteric artery in $4(28.57 \%)$ cases and descended below the caudal mesenteric artery in $7(50 \%)$ cases. In these 11 cases the distance between the ovarian arteries ranged from $0.97 \mathrm{~mm}$ to $11.17 \mathrm{~mm}$. But, in two individual there was no distance between right and left ovarian arteries. However, in a single individual there was two pair right and left ovarian arteries which were symmetrically originated and the distance from one pair to next pair is $15.4 \mathrm{~mm}$ (Fig. 8 ). The mean distance of the ovarian arteries and testicular arteries were $5.13 \pm 1.167$ and $3.3 \pm 1.03 \mathrm{~mm}$, respectively that were not statistically significant (Tab. 1).

The median caudal artery $(0.69 \pm 0.19 \mathrm{~mm})$ descended as a single vessel on the dorsal surface of the abdominal aorta above the bifurcation of external iliac arteries (Fig. 1, 2, 5) in all dissected rabbits. In a single individual $(3.57 \%)$, median caudal artery descended just opposite to the level of caudal mesenteric artery. On the other hands, it originated at various distance from caudal mesenteric artery.

The abdominal aorta in all the cases divided symmetrically into two common iliac arteries in lumbar region. The average diameter of right and left external iliac arteries were $1.79 \pm 0.29 \mathrm{~mm}$ and $1.72 \pm 0.35 \mathrm{~mm}$, respectively (Tab. 1 ).

Right $(0.65 \pm .11 \mathrm{~mm})$ and left $(0.64 \pm 0.12 \mathrm{~mm})$ profound iliac circumflex arteries showed small variation in their diameter and origination from external iliac artery (Tab. 1). Among 28 (100\%) cases, the left profound iliac circumflex artery descended at the same level of bifurcation of abdominal aorta in $2(7.14 \%)$ cases. Both right and left profound iliac circumflex arteries descended symmetrically from right and left external iliac arteries in $7(25 \%)$ cases. Right profound iliac circumflex artery descended first in relation to left profound iliac artery in $5(17.85 \%)$ cases. In another $14(50 \%)$ cases, the left profound iliac circumflex artery descended first than right one from the external iliac arteries (Fig. 1, 2, 7).

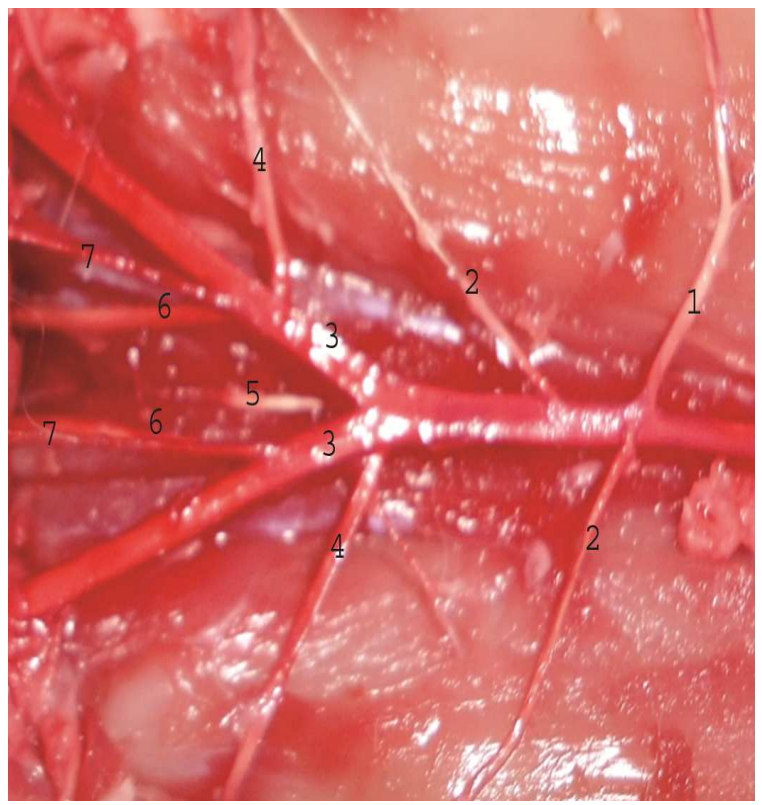

Figure 7. Division of normal pattern of two testicular arteries with branches of terminal portion of the external iliac arteries

1. Caudal mesenteric artery, 2. Testicular arteries, 3. External iliac arteries, 4. Profound iliac circumflex arteries, 5.Median caudal artery, 6. Internal iliac arteries, 7. Umbilical arteries 


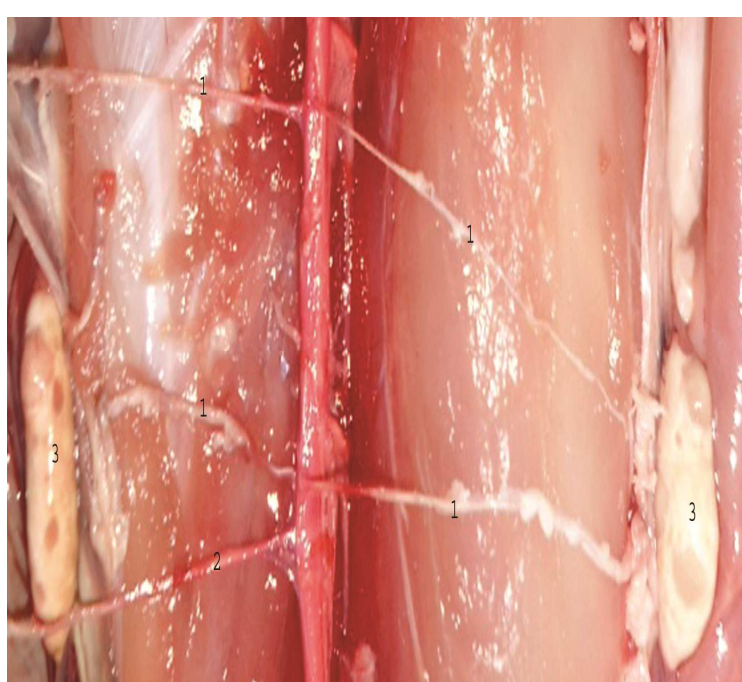

Figure 8. Division of exceptional origin of two pair of ovarian arteries

1. Ovarian arteries, 2. Caudal mesenteric artery, 3. Ovary

Internal iliac arteries showed a high variation in their location from the external iliac artery. In 5 (17.85\%) cases, right and left internal iliac arteries descended from external iliac arteries at the same level of right and left profound iliac circumflex arteries. But in another $23(82.15 \%)$ cases internal iliac arteries descended from external iliac arteries at various levels in relation to right and left profound iliac circumflex arteries. The average diameters of the internal iliac arteries were right $0.80 \pm .21 \mathrm{~mm}$ and left $0.79 \pm .19 \mathrm{~mm}$, respectively (Tab. 1). Umbilical arteries showed no variation in their location. In all the cases, umbilical artery originated at the level of internal iliac arteries (Fig. 1, 2, 7).

Average length of the abdominal aorta (aortic arch to bifurcation of common iliac arteries) was $19.11 \pm 1.22 \mathrm{~cm}$ (Tab. 2). But, average length of the abdominal aorta (at the place of descent of celiac trunk to bifurcation of common iliac artery) was $99.31 \pm 6.97 \mathrm{~mm}$. Mean distance between the celiac trunk and the cranial mesenteric arteries were $10.29 \pm 1.50 \mathrm{~mm}$ (Tab. 2). Almost in all the cases the diameter and length of major branches of abdominal aorta in male and female individual showed different values, but they were not statistically significant (Tab. 2). The diameter of the caudal mesenteric artery only showed significant $(p<0.05)$ difference in both sexes.

\section{DISCUSSION}

We have observed that the celiac artery is first major branch of the abdominal aorta, which descended as a single artery in all dissected rabbits. The number of researcher also showed to the similar results regarding celiac artery of the abdominal aorta in mammals $[16,17]$. However, variations in the celiac artery have been reported in many mammals such as in caprine, celiac-mesenteric trunk formed by the celiac artery and cranial mesenteric artery ${ }^{[18]}$, in human is formed by the celiac artery and the superior mesenteric artery ${ }^{[19]}$. We also have observed that celiac artery was divided into common trunk for hepatic, gastrodoudenal and right gastric artery and common trunk for splenic and left gastric artery in all dissected rabbit. Such pattern was described in dog ${ }^{[16]}$ and $41 \%$ in cat ${ }^{[20] .}$ The left gastric artery arose directly from the splenic artery in cats, dogs and pigs ${ }^{[14]}$ but directly from the celiac artery in horses and bovines, and directly from the hepatic artery in ovine [16]. Our study observed that hepatic artery, gastroduodenal artery and right gastric artery make another common trunk from the celiac artery in all the dissected rabbits. However, the hepatic artery of carnivores, bovines, swine and equines arises directly from the celiac artery ${ }^{[16,21]}$.

The cranial mesenteric artery descended as a second major branch from the abdominal aorta. The mesenteric artery is a unique vessel that comes out of the aorta a little caudal to the origin of the celiac

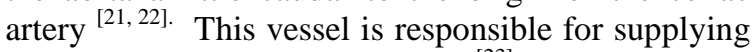
the largest part of small intestine ${ }^{[23]}$. In all the cases, it was a single descending vessel and descended on average $10.29 \pm 1.50 \mathrm{~mm}$ below the celiac trunk (Tab. $2)$. The similar findings were reported earlier ${ }^{[24]}$. However, the cranial mesenteric arose $1 \mathrm{~cm}$ caudal to the celiac artery in cat ${ }^{[25]}, 12 \mathrm{~cm}$ in the camel ${ }^{[26]}$ and just caudal to the celiac artery and sometimes by a common trunk with celiac artery in the ruminants ${ }^{[27]}$. We noticed that cranial mesenteric artery gives four major branches such as caudal pancreatico-duodenal artery, middle colic artery, ileocecocolic arteries and jejunal arteries in all the cases (Fig. 4). Caudal pancreatico-duodenal artery arose from the cranial mesenteric artery as a first branch in red fox, cat, and horse ${ }^{[28,29,3,30]}$ which was similar with our findings. Caudal pancreatico-duodenal artery arises distal to the ileocolic artery in carnivores [31]. On the other hand, in the camel, it arises from the jejunal artery that supplies the initial part of the jejunum ${ }^{[26]}$ and in goat; caudal duodenal artery and pancreatic branches are given separately from the cranial mesenteric artery ${ }^{[32]}$. As seen present study, the NZW rabbit possessed eighteen to twenty jejunal arteries. However the number of the jejunal arteries varies from species to species ${ }^{[31]}$. Their number is $15-19$ in carnivores that form a common trunk ${ }^{[33]}, 18-28$ in sheep ${ }^{[34]}, 15-22$ in the horse ${ }^{[29]}, 6$ or 7 in camel ${ }^{[26] \text {, }}$ 24 in goat ${ }^{[32]}, 8$ in red fox ${ }^{[30]}$. Jejunal arteries of all dissected NZW rabbit (Fig. 4) arose from the cranial mesenteric artery, at nearly regular intervals ${ }^{[30]}$.

Our study observed that cranial abdominal arteries descended from renal arteries in 27 cases but in a single case only left cranial abdominal arteries arose from the abdominal aorta directly not from left renal artery with similar record from the abdominal aorta in carnivores ${ }^{[8]}$.

Renal arteries descend from the abdominal aorta in all dissected rabbit. Although the origin of both renal arteries from the abdominal aorta varied, right renal artery descended cranial to the left renal arteries in $27(96.43 \%)$ cases. Similar relation was observed in 
14 species (Human, Chimpanzee, Baboon, Pig tailed monkey, Stump faced monkey, Capuchin, greater Japanese shrew mole, lesser Japanese mole, rat, mongoose ,mouse ,rabbit, dog, hippopotamus) . But in a single case both renal artery originated at same level in our experiment. The same relation was reported in gibbon, marmoset, loris and pig ${ }^{[35]}$.

Ovarian and testicular arteries descended asymmetrically from the abdominal surface of the aorta above or below the caudal mesenteric artery. In male, $6(42.86 \%)$ cases right testicular arteries descended first than left and in $7(50 \%)$ cases, left testicular arteries descended first than right. But in a single case there was no distance between two testicular arteries. Many authors described that it originated immediately behind the origin of the inferior mesenteric artery in rabbit ${ }^{[36]}$, supporting the present findings. Same pattern was also observed in carnivores ${ }^{[35]}$. But in guinea pigs, the ovarian artery originated either from the aorta at about the level of origin of the renal arteries, direct branches of renal arteries, or common trunks with renal artery and in some cases formed anastomoses with branches of the renal arteries. Whereas left renal artery originated from the abdominal aorta slightly caudal to the renal arteries in rat ${ }^{[37]}$. In female, $8(57.45 \%)$ cases right ovarian arteries descended first than left and in 5 $(35.42 \%)$ cases left ovarian arteries descended first then right. In exception, double pair ovarian artery was observed in a single case in this study.

Profound iliac circumflex arteries show a variation in their origin in all dissected rabbits. Most often symmetrical profound iliac circumflex arteries descended from external iliac arteries which were observed in cat ${ }^{[20]}$. External iliac arteries in all the cases descended symmetrically from the abdominal aorta in our study. The occurrence of symmetrical descent of external iliac arteries can be identified in $87.5 \%$ of $\operatorname{dogs}{ }^{[36]}$ and $58 \%$ of cats ${ }^{[20]}$. Internal iliac arteries descended from external iliac arteries at different height in all the cases. Umbilical artery descended at the level of origin of internal iliac artery in all the cases.

Almost in all the cases the diameter and length of major branches of abdominal aorta in male and female individual showed different values, but they were not statistically significant (Tab. 1,2). Only the lumen of the caudal mesenteric artery in male showed significantly $(p<0.05)$ larger diameter giving focus on more blood flow during surgery as well as clinico-pathological and biomedical research importance.

\section{ACKNOWLEDGEMENTS}

All the praises and deepest sense of gratefulness belongs to the Almighty ALLAH, the Merciful, the omnipotent, and the Beneficent but the supreme Ruler of the Universe Who enabled me to complete my research work successfully. The author sincerely desire to express his deepest sense of gratitude to his teacher Professor Dr. Mohammad Abul Quasem and Professor Dr. Mohammad Lutfur Rahman,
Department of Anatomy and Histology, Chittagong Veterinary and Animal Sciences University, Khulshi, Chittagong for his guidance and affectionate feeling during the entire period of research work and preparation of this manuscript.

\section{REFERENCES}

1. Barone R, Pavaux C, Blin PC, Cuq P (1973). Atlas of anatomy of the rabbit. Masson and Co, Paris.

2. Hebel R, Stromberg MW (1976). Anatomy of the laboratory Rat. Baltimore: Wiliams and Wilkins co., Baltimore.

3. Hudson, Hamilton (1993). Atlas of feline anatomy for veterinarians. 1st Ed. W.B. Saunders, M.A Philadelphia, London.

4. Popesko P, Rajtova V, Horak J (1992). A colour atlas of anatomy of small laboratory animals. Wolfe Publishing, Ltd., London.

5. Rajtova V, Danko J (2001). Vasculature of the testis, epididymidis and ductus deferens of rabbit. The Arteries. Act. Vet. Brn. 70 (6): 3-7.

6. Miller MF (1964). Anatomy of the dog. Philadelphia, London-Toronto.

7. Dabanolgu I (2000). A quantitative study of the aorta of the New Zealand rabbit (Oryctolagus cuniculus). Anat. Hist. Emb. 29: 145-147.

8. Brudnicki W, Macherzynska, Nowicki W (2007). Variation in the arteries of the aortic arch in European brown hare (Lepus europaeus). E. J. Polis. Agri. Uni. 10 (1): 2-5.

9. Cizkova D, Kafka J, Cizek M, Sevcik A, Marsala J (2001). The cauda equina syndrome induces synthesis of stress proteins. In Psy. 5: 15-16.

10. Jorgensen L, Packham MA, Rowsell HC, Mustard F (1972). Deposition of formed elements of blood on the intima and signs of intimal injury in the aorta of rabbit, pig and man. Lab. Invest. 27: 341-350.

11. Kent KC, Wroblewski L, Jackman RW, Skillman JJ (1995). Platelet attachment stimulates endothelial cell regeneration after arterial injury. Surgery. 117: 276-281.

12. Parish MA, Grossi EA, Baumman FG, Asai T, Rifkin DB, Colvin SB (1995). Effects of a single administration of fibroblast growth factor on vascular wall reaction to injury. Ann. Thorac. Surg. 59 (4): 948-954. 
13. Mackey ME, Wu Y, Hu R, DeMaro JA, Jacquin MF, Kanellopoulos GK, Hsu CY, Koucoukos NT (1997.) Cell death suggestive of apoptosis after spinal cord ischemia in rabbits. Stroke. 28(10): 2007-2012.

14. Nielson VG, Weinbroum A, Tan S, Samuelson PN, Gelman S, Parks DA (1995). Xanthine oxidase inactivation attenuates post-occlusion shock after descending thoracic aorta occlusion and reperfusion in rabbits. $J$. Thorac. Cardiovasc. Surg. 110: 715-772.

15. Freestone TR, Turner J, Higman DJ, Lever JT, Powel JT (1997). Influence of hypercholesterolemia and adventitial animation on the development of aortic aneurysm in rabbits. Art. Thromb. Vasc. Biol. 17: 10-17.

16. Abidu-Figueiredo M, Dias GP, Cerutti S, Carvalho-De-Souza B, Maia RS, Babinski MA (2005). Variations of celiac artery in dog: anatomical study for experimental, surgical and radiological practice. Int. J. Morph. 23 (1): 3742.

17. Bednarova Z, Malinovsky I (1984). Ramification of celiac artery in the domestic cat. Folia Morph. 34 (1): 36-44.

18. Langenfeld M, Pastea E (1977). Anatomical variants of the celiac artery in sheep with special reference to the celiomesenteric arterial trunk. Anat. Anz. 142: 168-174.

19. Cicekcibasi AE, Uysal H, Seker M, Tuncer I, Büyükmumcu M, Salbacak (2005). A rare variation of the coeliac trunk. Ann. Anat. 4: 421-7.

20. Berg R (1961). Comprehensive research on the course of the aorta branches in Felis domestica. Anat Anz. 110: 224-250.

21. Nickel R, Schummer A, Seiferle E (1983). The Anatomy of the Domestic Animals. Verlag Paul Parey, Berlin.

22. Getty R (1975). The Anatomy of the Domestic Animals. W.B. Saunders Com.

23. Sissin S (1943). The anatomy of the domestic animals. W.B. Saunders Com., Philadelphia and London.

24. Uddin M, Rahman ML, Alim MA, Ahasan ASML (2012). Anatomical distribution of cranial and caudal mesenteric artery in white New Zealand rabbit. Int. J. Nat. Sci. 1(2).

25. Reighard J, Jennings HS (1966). Anatomy of the cat. Third and enlarged Edition. Holt, Rinehart and Winston. New York. Chicago, San Francisco. Toronto. London.

26. Smuts MMS, Bezuidenhout AJ (1987). Anatomy of the dromedary. Clarendon Press. Oxford.

27. Habel RE (1975). Ruminant digestive system. In: S.Sisson and J. D. Grossman (Ed.) The Anatomy of the Domestic Animals (5th Ed.). W.B. Saunders Co., Philadelph.

28. Ghoshal NG (1975a). Carnivores heart and arteries. In: Sisson and Grossman's The Anatomy of the Domestic Animals, p. 15941651. Vol. 2 (5th ed). R. Getty (ed.), W.B. Saunders com, Philadelphia.

29. Ghoshal NG (1975b). Equine heart and arteries. In: Sisson and Grossman's The Anatomy of the Domestic Animals, p. 554-618. Vol. 2(5th ed). R. Getty (ed.), W.B. Saunders com, Philadelphia.

30. Hatem B (2007). Some anatomical studies on the mesenteric arteries in the red fox (Vulpes vulpes) Ph. D. Thesis. Fac. Vet. Med. Benha Univ. Egypt.

31. Schummer A, Wilkens H (1981). The circulatory system, the skin and the cutaneous organs of the domestic mammals. $1^{\text {st }}$ Ed. Verlag Paul Parey Berlin Hamburg.

32. Yousef GAE (1991). Some Anatomical studies on the celiac, cranial mesenteric and caudal mesenteric arteries of goat. Ph. D. Thesis. Fac. Vet. Med. Zag. Univ. Benha branch. Egypt.

33. Thamm H (1941). The arterial blood supply of the gastrointestinal tract, its annex glands (liver, pancreas) and the spleen in dogs. J. Morph. 85: 417-446.

34. Happich A (1961). Blutgefassversorgung the digestive organs in the abdomen and pelvis screed including liver, spleen and pancreas in sheep. Inaugural dissertation, Hanover.

35. Yokota E, Kawashima T, Ohkubo F, Sasaki H (2005). Comparative Anatatomical Study of the Kidney Position in Amniotes Using the Origin of the Renal Artery as a Landmark. Okajimas. Folia. Anat. Jpn. 81(6): 135-142.

36. Berg R, Smollich A (1962). Comprehensive research on the second branch of A. subclavia in Canis familiaris. J. Mon. Vet. 1962, 17, 307315.

37. Craigie EH (1969). Bensley's practical anatomy of the rabbit .8th Edn. Toronto Press, Canada. 